\title{
Workshops for Learning in Computational Fluid Mechanics
}

\author{
M. T. Parra \\ University of Valladolid \\ Ell. Paseo del Cauce 59 \\ 47011 Valladolid (Spain) \\ (+34) 983184536 \\ terpar@eii.uva.es
}

\author{
J. R. Pérez \\ University of Valladolid \\ Ell. Paseo del Cauce 59 \\ 47011 Valladolid (Spain) \\ (+34) 983184536 \\ jrubenpd@gmail.com
}

\author{
F. Castro \\ University of Valladolid \\ EII. Paseo del Cauce 59 \\ 47011 Valladolid (Spain) \\ (+34) 983423365 \\ castro@eii.uva.es
}

\begin{abstract}
The must-do of teaching Computational Fluid Dynamics (CFD) is the practical component. The main aim of the present paper is to propose test cases used in research. When these benchmarks are conveniently scaled-down and parameterized, students improve their understanding of the strong and weak points of the numerical models and gain an insight into the fluid dynamics processes learnt in the classroom. The goal is to prepare students who are new in this area to become self-sufficient in engineering practice.
\end{abstract}

\section{Categories and Subject Descriptors}

K.3 [Computer and Education]: Computer Uses in Education. Collaborative learning, distance learning. - Information and communications technology (ICT).

\section{General Terms}

Documentation.

\section{Keywords}

Moodle, workshop, Computational Fluid Dynamics (CFD).

\section{INTRODUCTION}

Computational fluid dynamics is a key design tool in mechanical engineering. Its growth in recent years has been bolstered by the increased calculating power of computers. There are many commercial company codes that prove relatively straightforward to use, although the danger lies in using the codes as a kind of black box where information is introduced and output is produced. Understanding the basics and being able to identify the weaknesses of the commercial codes is essential. Adopting a critical approach which takes into account that the validity of the results is subject to the conditions imposed and the calculation model chosen is equally important, as is valuing the usefulness of the outcomes based on the uncertainty inherent when validating classical benchmark using known solutions.

All of these skills can only be acquired through practice [1] and by carrying out projects which are appropriately scaled down to suit bachelor degree courses (see figure 1), yet applying structures and stages for projects that may be undertaken in the real world, either in a design office or a research laboratory.

Permission to make digital or hard copies of all or part of this work for personal or classroom use is granted without fee provided that copies are not made or distributed for profit or commercial advantage and that copies bear this notice and the full citation on the first page. Copyrights for components of this work owned by others than ACM must be honored. Abstracting with credit is permitted. To copy otherwise, or republish, to post on servers or to redistribute to lists, requires prior specific permission and/or a fee. Request permissions from Permissions@acm.org.

TEEM '14, October 01 - 03 2014, Salamanca, Spain Copyright 2014 ACM 978-1-4503-2896-8/14/10...\$15.00 http://dx.doi.org/10.1145/2669711.2669888
The actual framework of ICT offers a wide range of tools to provide individual and distance learning [2]. This paper involves the development, implementation and evaluation of an educational workshop, using the Moodle platform for Mechanical Engineering students to learn Computational Fluid Dynamics at the user level. Learning computational fluid must be eminently practical, therefore any theoretical approach is doomed to failure. The realization of a first numerical modeling project under the guidance of a teacher unfolds a world of possibilities for students who want to further deepen the topic. It intends to develop a set of easily understandable tasks that students can independently perform to further the use of this tool. Skills in computational fluid mechanics have significant weight while working in consulting and research centers.

The aim is for the student, either independently or under the supervision of the professor, to learn how to gain a deeper understanding of the use of this extremely powerful tool, whilst always validating it with results from other sources and making a rational use of computational resources. The tasks selection is the result of teaching experience in computational fluid dynamics at the University of Valladolid (Spain) over the last ten years. The final course is established as digital teaching unit of Mechanical Engineering undergraduates. A similar experience was successfully carried out at the universities of Iowa, Iowa State and Cornell in 2006 [3].

Information has been gathered from the following test cases which may be considered for inclusion as possible workshops through having a sufficient number of results with which to validate the model and because they evidence interesting flow patterns. The aim was to find cases with an industrial application, either lubrication, vehicle aerodynamics, or industrial boilers, but whose geometry can be modeled in $2 \mathrm{D}$ so that reasonable results can be achieved at low computational cost using low-end personal computers. They should also allow for certain parameterization so that various groups can carry out the same project but with different parameters that will enable students to share their results.

\section{LAYOUT OF THE INNOVATION PROJECT}

Dale [4] evidenced in 1969 that the retention capacity was around the $75 \%$ when the student have an active role on a practical task. Beside, the comprehension of concepts is an invaluable aspect. The following steps describe the development of the practical course [5].

Step 1: Develop tasks in the Moodle platform that allow show whether the student has assimilated the basics of computational fluid mechanics.

Step 2: Build a library of workshops with computational fluid dynamics projects covering the following stages: sensitivity 
analysis the mesh, convergence analysis different numerical algorithms, correct implementation of turbulence models in the vicinity of the wall, turbulence model selection based on validation with experimental results.

Step 3: Develop tasks that allow peer interaction not only in the evaluation phase, but also synthesizing the results of different groups of students in the construction of graphs that evidence the uncertainties facing accurate experimental results.

\section{SKILL ACQUISITION}

In CFD learning, it is essential to learn by creating a model which has a specific application. The present article offers a compilation of conveniently referenced benchmarks which not only allow students to acquire skills in the field of computational fluid dynamics but also to grasp concepts learnt in other fluid dynamics and fluid machines courses. One pre-requisite for the chosen projects was that they should meet a serie of requirements: they should be straightforward from the geometric standpoint as well as offering complex flow patterns which are sufficiently well documented in the references.

Have been developed four workshops with their parameterization using more than 25 different cases and the corresponding results to validate the models. Thus, each student makes a project of a similar difficulty but with different flow patterns, allowing a better understanding of concepts learned in other subjects. The parameterization enables students to pool their results concerning the influence of the parameter on the system's performance once projects are concluded.

Each project is structured in four stages and an assessment scale has been devised for each stage, see figure 2 .

These are the possible stages of the work:

1.- Analysis of mesh sensitivity: with basic configuration based on turbulence model and calculation algorithm. This should be refined in the areas of interest until the increase of spatial resolution does not affect the results.

2.- Influence of the resolution algorithm: using the mesh with the smallest number of cells such that the results do not change, carry out simulations with different algorithms. Choose the one which shows the best convergence (minimum time consuming).

3.- Influence of the turbulence model: using the previously chosen mesh and algorithm, carrying out simulations with a range of turbulence models. The model offering the best validation with the experimental results should be selected.

4.- Description of the fluid field: describing floe patterns using terms appropriate to the field of fluid dynamics. Obtaining certain data resulting from post-processing of the values given by the code such as power dissipated in a driven cavity, head losses, efficiency of the device ...

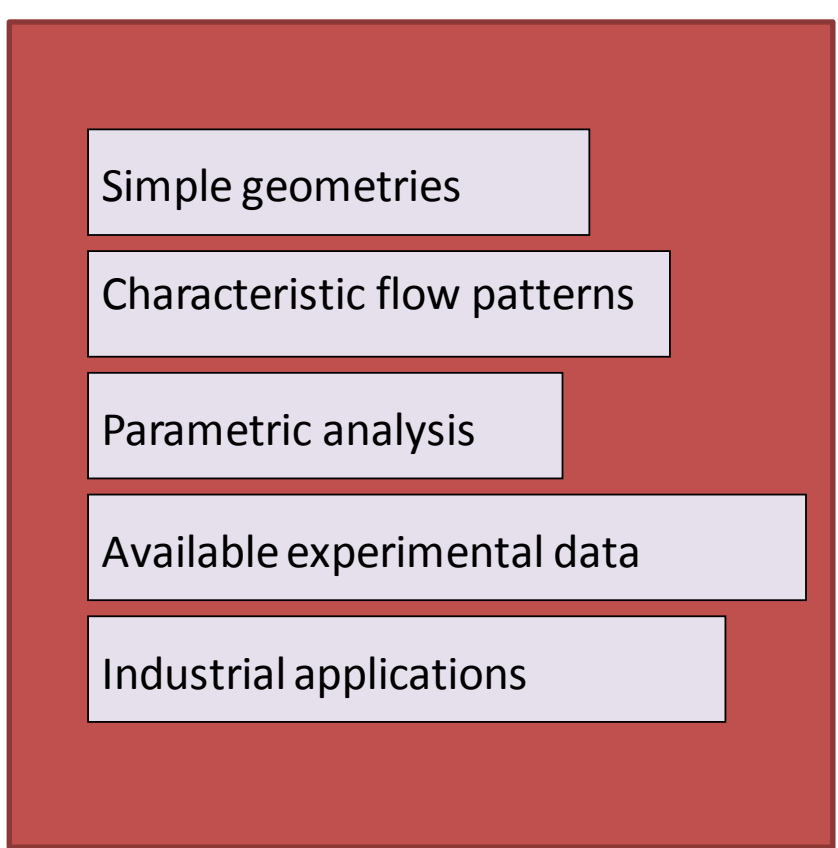

Figure 1. Prerequisites of the practical workshops.

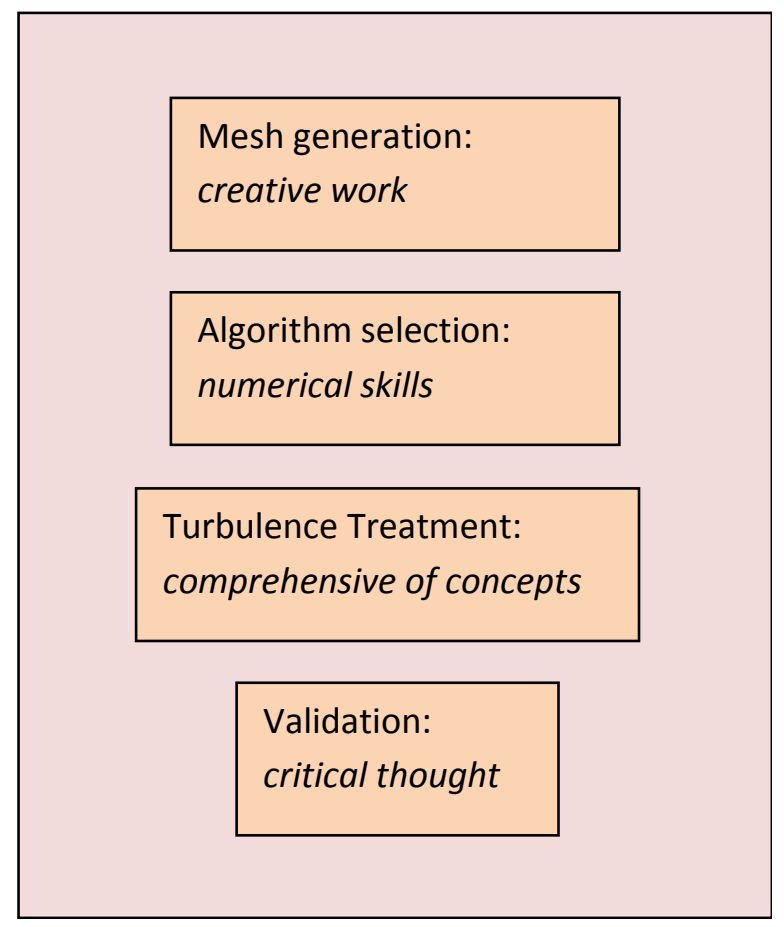

Figure 2. Outline of a workshop with the acquisition of skills.

A scale was created to rate the reports of the projects and to guide students on the steps involved in any project of Computational Fluid Dynamics. They assess the use of lexical characteristic of Computational Fluid Mechanics, As well as the strategy to improve the numerical model, the ability to synthesize the results and conclude the weak points. Therefore consistency when assuming important decisions and developing their critical thought are the aims of the workshop.

Although the project work at the scale of a CFD course may be completed in less than 10-15 hours, previous experience had 
shown that most students tended to take too long over the initial stage of the mesh sensitivity analysis, and devote less attention to processing the resolution algorithm and selecting the turbulence model or do so mechanically. The approach of breaking down the project assessment into stages sorted out that issue.

The aim of the project is to adopt a critical approach to the results obtained and to develop strategies for improving the results. The conclusion to be drawn is that the reliability of the model is linked to the accuracy obtained with the validation based on experimental results. One further conclusion concerns the need to make efficient use of computational resources. Obtaining reasonably good results using the smallest possible number of cells in the computational domain is essential.

\subsection{Peer evaluation}

Actual scenario of engineering students evidence their deep theoretical knowledge and a lack of transfer to the applied field. Students do not have the feeling if their work is good enough or not. Then the evaluation of each task is done by students as well as the professor following the strict scale. While students anonymously evaluate the work of their partners, they get a different point of view. They can notice their task had either more or less strong evidences of critical analysis.

The role of evaluator is a precursor of understanding their degree of achievement. Also, any score lower than the maximum should be justified. Obviously, professor score is weightier than the students score. The final score is result of both: the task and the evaluation.

So far, the collaborating task of sharing the results of every student to see if tendencies match the global graph, was not evaluated because some parameters might be more difficult to model than others. However, students are very motivated to avoid that their results were outliers on the final graph with experimental results and results of other students.

\section{SAMPLE OF WORKSHOPS}

The range of projects offered includes renewable energies such as wind turbines, reactive flows as burners, lubrication, and vehicle aerodynamics.

Table 1.- Projects to be carried out to help learn computational fluid dynamics codes.

\begin{tabular}{|c|c|c|}
\hline & Brief description & Ref. \\
\hline 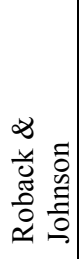 & $\begin{array}{l}\text { General combustor model. The geometry is } \\
\text { straightforward since it comprises two coaxial } \\
\text { ducts and rapid expansion. The flow pattern } \\
\text { is given by the interaction of coaxial jets. } \\
\text { This results in the appearance of two } \\
\text { recirculation regions depending on the swirl } \\
\text { number of the peripheral jet. }\end{array}$ & {$[6]$} \\
\hline$\underset{\Delta}{\mathbb{s}}$ & $\begin{array}{l}\text { An H-Darrieus with a different operating } \\
\text { conditions, airfoils and solidities perform as } \\
\text { wind turbine. Using } 3 \text { strait blades of the } \\
\text { NACA family produces a periodic flow with } \\
\text { a wake of different intensities }\end{array}$ & [7] \\
\hline
\end{tabular}

\begin{tabular}{|c|c|c|}
\hline 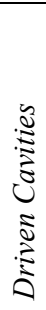 & $\begin{array}{l}\text { Cavity with a moving wall to cause } \\
\text { movement of the fluid contained therein. } \\
\text { The flow patterns display swirls (one main } \\
\text { and several secondary ones), instabilities, } \\
\text { transition to turbulence. The result is the } \\
\text { appearance of multiple recirculation regions } \\
\text { depending on the Reynolds number and the } \\
\text { geometry. }\end{array}$ & [8] \\
\hline 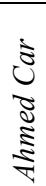 & $\begin{array}{l}\text { General model of a car which, with a simple } \\
\text { geometry, displays complex flow patterns. } \\
\text { This results in the appearance of different } \\
\text { recirculation regions depending on the } \\
\text { different angles of inclination of the tailgate. }\end{array}$ & [9] \\
\hline
\end{tabular}

\subsection{Swirling burner}

As a sample of swirling burner, students reproduce the case of Roback and Johnson [6] that provides experimental results for both isothermal and reactive cases, see figure 3. Contrasting results of different teams, students evidence different flow patterns associated to different swirling intensities.
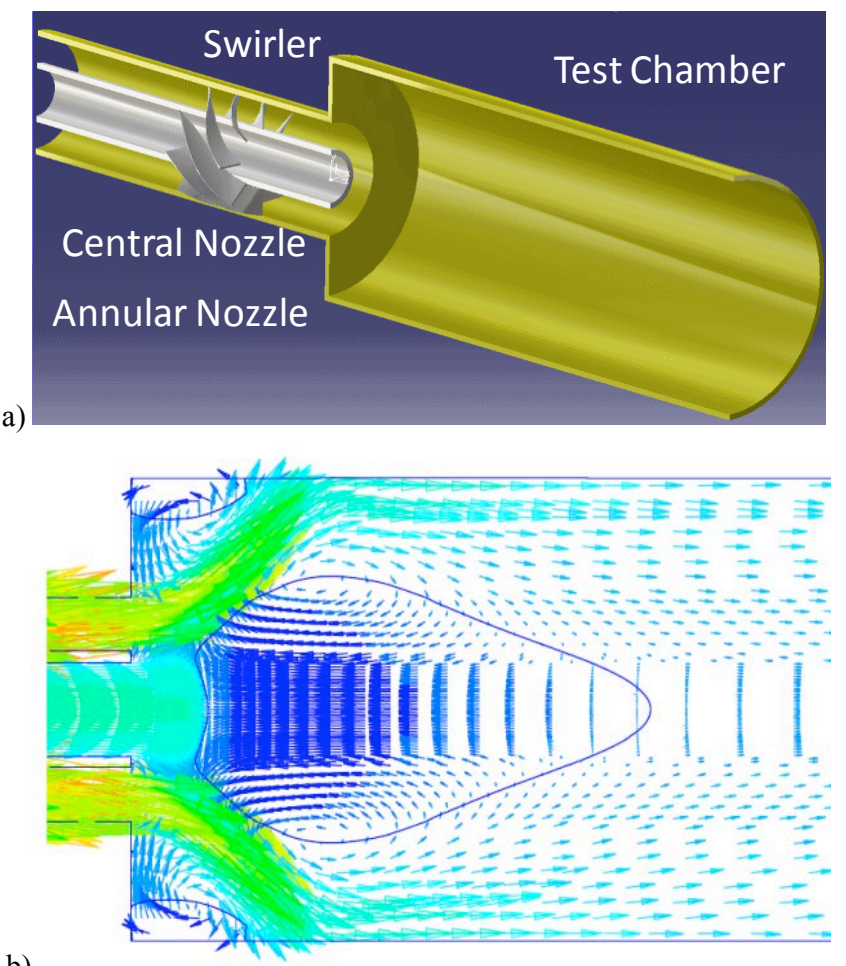

Figure 3. a) Scheme of the swirling burner. b) Velocity vectors for Swirl number unity.

\subsection{Vertical Axis Wind Turbine}

Another workshop is the performance of a vertical axis wind turbine of the type H-Darrieus [7], where students solve the transient behavior of the rotor while spinning, see figure 4 . Each team has a different operating conditions and every team collaborates on the building of the characteristic curve of power coefficient of the wind turbine. 


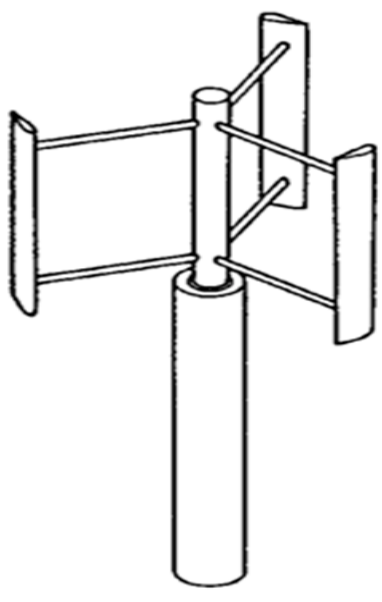

a)

b)

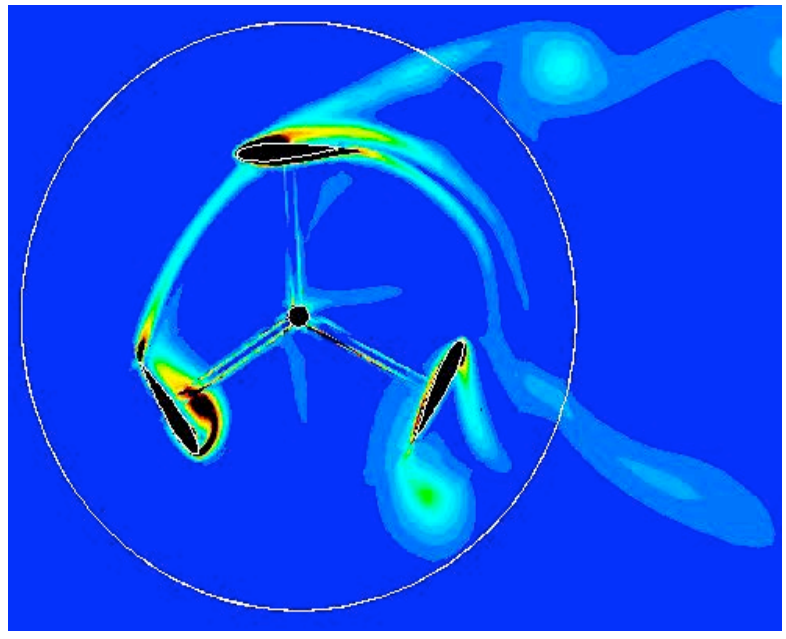

Figure 4. a) Scheme of H-Darrieus b) Wake of NACA 0025 solidity unity operating on design conditions.

Students learn about aerodynamics, turbo machinery and gain an understanding of the performance of these devices.

\subsection{Driven Cavity}

Driven cavities are an important source of benchmark [8] to validate the performance of numerical models with different geometries and Reynolds numbers that help to understand the flow patterns in lubrication, see figure 5 . The moving wall induces a primary and several secondary vortices.

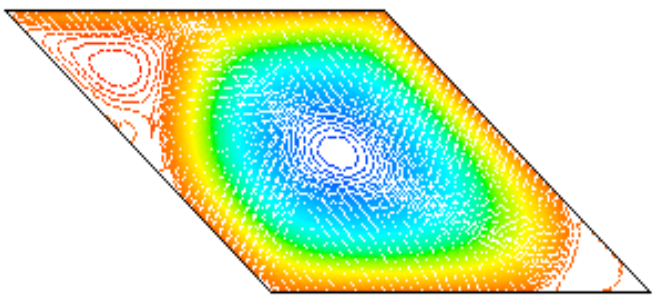

Figure 5. Stream lines in a skewed driven cavity

\subsection{Ahmed Car}

This project is a classical test of the aerodynamics of a general model of a car, [9] depending on the inclination of the tailgate at $25^{\circ}$ or $35^{\circ}$. Flow validation is only in the vehicle's longitudinal plane, see figure 6 .

a)

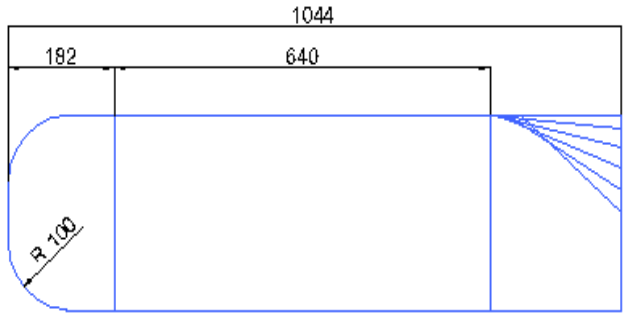

b)

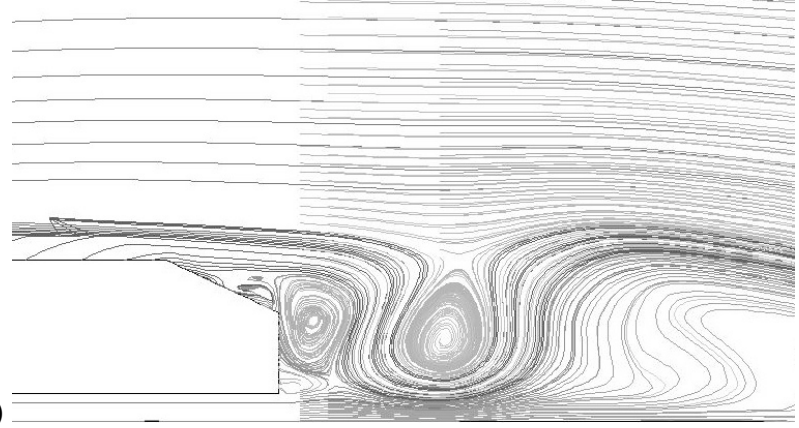

Figure 6. a) Scheme of the Ahmed car. b) Stream lines downwards of a car.

\section{SURVEY RESULTS}

Taking advantage of the end of each semester, the students who have completed a Computational Fluid Dynamics (CFD) fill up a survey to establish their satisfaction, [10]. Resulting that they thank the practical teaching method and therefore theoretical concepts are better understood.

A survey was drawn up using student feedback in order to gauge the level of satisfaction when learning a code of Fluent computational fluid dynamics when doing a collaborative workshop in Moodle. A $60 \%$ of the students enrolled on the course in question filled out the survey, the overall results of which are summed up in figures 7 and 8 .

A certain degree of satisfaction is clearly evident and, more importantly, students' confidence in their ability to cope with a CFD project on their own is reflected. It is also significant that the aerodynamics project helps to improve understanding of the concepts dealt with in the classroom.

As for open answers, students demand more variety of possible workshops and manifested difficulties in identifying the physical phenomena that cause fluid field behavior. Actually they have enough knowledge, but it was the first time they face the diagnosis of the cause of certain flow patterns.

It is this connection between the concepts learned in previous subjects in theory and simple industrial applications what was most appreciated by the students when identifying the connection theory and application. 
Workshops for learning in Computational Fluid Mechanics

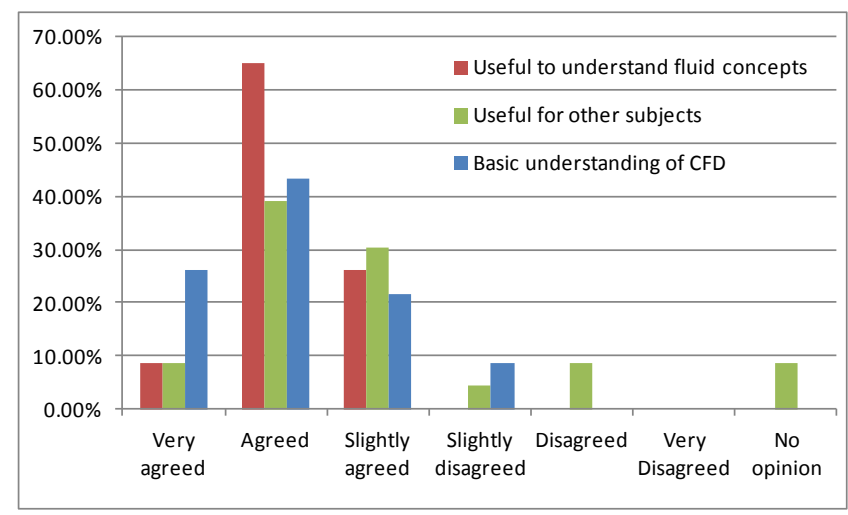

Figure 7. Results of the survey regarding the utility of the workshop.

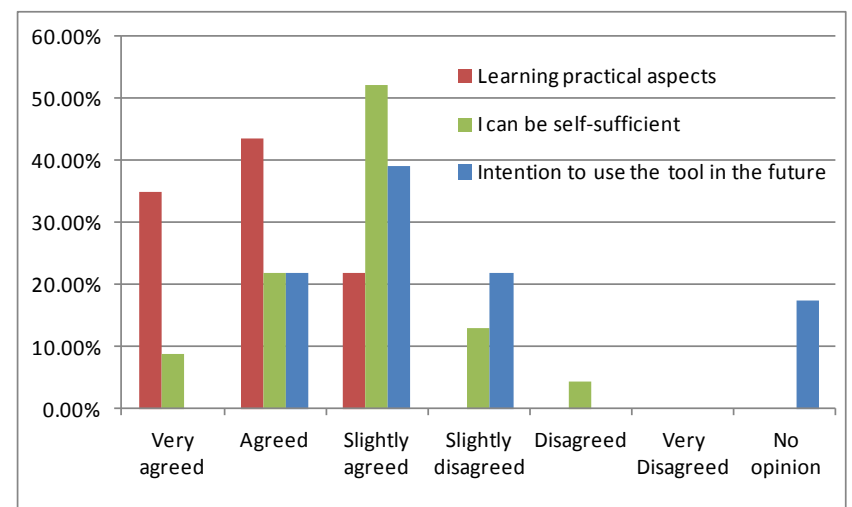

Figure 8. Results of the survey regarding the satisfaction of the workshop.

Another aspect is the outstanding rate of success of this course. A little percentage of the students find the project as a pastime and they invest spare time and are anxious to continue in a deeper level.

Students are a little concern about their ability to be self sufficient. However, the students that carry out the final project to get the degree using CFD agree that the learning was very useful.

A future task is to expand the range of projects offered including renewable energies such as water turbines, environment issues and prediction of emissions, ventilation to study comfort.

\section{CONCLUSIONS}

The use of ICT in the Virtual Campus of the University of Valladolid is highly appreciated by the students. Moreover, the gradually overcome of consecutive tasks; let the students realize that they know more than their priori perception.

The actual implementation of the project simplified to teaching scale, allows the students to apply concepts from other subjects. In the end, students realize that, any work ends up being multidisciplinary and many technological aspects are linked.

The scalability of the project must provide results with a reasonable approach to the flow features and poor computational resources.
When the benchmarks are conveniently scaled-down and parameterized, students improve their understanding of the strong and weak points of the numerical models.

Students gain collateral skills as critical thought and creativity while they work in a collaborative ambient.

\section{ACKNOWLEDGMENTS}

The author thankfully acknowledges the University of Valladolid for the projects of Educational Innovation (ref. PID/2011/78, PID/2013/7 and PID/2014/30).

Besides, this research was a collateral contribution of the project reference ENE2011-25468 from the Spanish Ministry of Science and Innovation.

\section{REFERENCES}

[1] K-C. Feng, B. Chang, C-H. Lai \& T-W. Chan. Joyce: A Multi-Player Game on One-on-one Digital Classroom Environment for Practicing Fractions, (2005) Proc. of the Fifth IEEE International Conference on Advanced Learning Technologies (ICALT'05).

[2] Brown, J. S., Growing Up Digital: How the Web Changes Work, Education, and the Ways People Learn. (2002)United States Distance Learning Association.

[3] Stern F. Xing T. Yarbrough D.B. Rothmayer A. Rajagopalan G. et. al. Hands-On CFD Educational Interface for Engineering Courses and Laboratories. Journal of Engineering Education, (January 2006), pp. 63-83 DOI= http://onlinelibrary.wiley.com/doi/10.1002/j.21689830.2006.tb00878.x

[4] E. Dale, Audio-Visual Methods in Teaching. (1969) New York: The Dryden Press.

[5] T. Parra, Aprendizaje Práctico de Mecánica de Fluidos Computacional usando TIC, (2013) V Congreso Internacional Latina de Comunicación Social. ISBN-13: 97884-15698-29-6 / D.L.: TF-715-2013

[6] R. Roback, B.V. Johnson, Mass and momentum turbulent transport experiments with confined swirling coaxial jets, (1983) NASA CR-168252.

[7] N.C. Uzarraga, A. Gallegos, M.T. Parra, J.M.Beltran, Numerical Analysis of Airfoils used at VAWT, (2012) ASME ESFuelCell2012-91113

[8] E. Erturk, \& B. Dursun, Numerical solutions of 2-D steady incompressible flow in a driven skewed cavity. Journal of Applied Mathematics and Mechanics, Vol 87 (2007) pp 377392.

[9] S.R. Ahmed. Wake structure of typical automobile shapes. Journal of Fluids Engineering, Transactions of the ASME, 103 (1981) 162 - 169.

[10] M.T. Parra Santos, Metodología Docente de Mecánica de Fluidos Computacional V Jornada de Innovación Docente "Innovar para crecer, crecer para innovar. (2013) Universidad de Valladolid. 